\title{
Laparoscopic repair of congenital pleuroperitoneal hernia using a polypropylene mesh in a dog
}

\author{
[Correção laparoscópica de hérnia pleuroperitoneal utilizando \\ malha de polipropileno em cão] \\ H.F. Hartmann ${ }^{1}$, P.C. Basso ${ }^{1}$, K.L. Faria ${ }^{1}$, M.T. Oliveira ${ }^{1}$, F.W. Souza ${ }^{1}$, É.V. Garcia ${ }^{1}$, \\ J.P.S. Feranti ${ }^{1}$, M.A.M. Silva ${ }^{2}$, M.V. Brun ${ }^{1}$ * \\ ${ }^{1}$ Universidade Federal de Santa Maria - Santa Maria, RS \\ ${ }^{2}$ Universidade de Passo Fundo - Passo Fundo, RS
}

\begin{abstract}
Pleuroperitoneal hernias are the most uncommon type of diaphragmatic hernias in dogs and cats. The treatment of choice is surgery and may involve the use of prosthetic implant through celiotomy. In the current report, laparoscopic repair of a congenital pleuroperitoneal hernia using polypropylene mesh in a dog is described. The surgery was feasible. Appropriate reduction of the hernia was carried out and no complications were noted.
\end{abstract}

Keywords: diaphragmatic hernia, congenital defect, videosurgery, canine

\section{RESUMO}

Hérnias pleuroperitoneais são o tipo mais incomum de hérnias diafragmáticas em cães e gatos. $O$ tratamento de escolha é cirúrgico e pode envolver o uso de implantes protéticos na abordagem via laparotomia. No presente relato, é descrito o reparo de uma hérnia pleuroperitoneal congênita através de laparoscopia com utilização de malha de polipropileno. A cirurgia foi viável. Houve redução apropriada da hérnia sem observação de complicações.

Palavras-chave: hérnia diafragmática, defeito congênito, videocirurgia, canino

\section{INTRODUCTION}

Diaphragmatic defects occur most commonly due to trauma, but may also be associated with congenital abnormalities such as peritoneopericardial hernia, hiatal hernia, and less frequently, pleuroperitoneal hernia (Cariou et al., 2009). Congenital diaphragmatic hernias are developmental defects of the diaphragm that allow the passage of abdominal viscera into the chest. The occurrence of congenital diaphragmatic hernias in humans is of $1 / 2200$ births (Hedrick, 2010). In pleuroperitoneal hernias, the synthesis of collagen and muscular tissue that divides the pleura and peritoneum ceases prematurely in the embryonic phase (Cariou et al., 2009), and the transverse septum or pleural and peritoneal folds do not fuse. Thus, an incomplete diaphragm that allows the free displacement of viscera is formed (Thrall, 2010). The serous surface of the thoracic diaphragm remains intact, preventing direct communication between the pleural and peritoneal cavities (Cariou, 2009).

The severity of the disease is associated with the degree of pulmonary hypertension and hypoplasia resulting from internal pressure within the thorax, as well as the presence of concomitant malformations (Kesieme and Kesieme, 2011). Patients may present mild signs of respiratory dysfunction or even be asymptomatic (Burns et al., 2013).

Recebido em 28 de abril de 2014

Aceito em 7 de julho de 2015

* Autor para correspondência (corresponding author)

E-mail: mauriciovelosobrun@hotmail.com 
Chest radiography is the most important diagnostic tool if diaphragmatic abnormalities issuspected . Echography, computed tomography and magnetic resonance may also be considered (Hedrick, 2004; Cariou, 2009).

The treatment of choice for diaphragmatic hernia repair is surgery, regardless of its severity (Beck et al., 2004). Surgical repair of diaphragmatic hernias can be safely achieved using several techniques. Transthoracic and transabdominal approaches, as well as laparoscopic-assisted, laparoscopic and thoracoscopic techniques were described. Primary occlusion of the defect is the main goal of surgery. Thus, prosthetic implant or muscle flap techniques may be required when proper apposition is lacking or reduced, with extreme tension on the defect's edges (Kesieme and Kesieme, 2011).

The aim of the current study was to report the first successful case of laparoscopic reduction of a rare pleuroperitoneal hernia using polypropylene mesh in a dog.

\section{CASE DESCRIPTION}

A two-month-old Cimarron bitch, weighting $4.4 \mathrm{~kg}$, was admitted presenting dyspnea and recurrent vomiting. The patient presented normal behavior, despite being underdeveloped in comparison to the puppies of the same progeny. On physical examination, the patient presented regular nutritional status and hydration, normochromic mucosa, $38.3^{\circ} \mathrm{C}$ of core temperature and normal lymph nodes. Cardiac auscultation revealed tachycardia, while the chest showed pulmonary crackles. Ventrodorsal chest radiography showed cranioventral protrusion of the diaphragm (Fig. 1-A), whereas the same volume increase was present in ventral position on the laterolateral projection (Fig. 1-B). A suspicion of congenital diaphragmatic hernia was established.

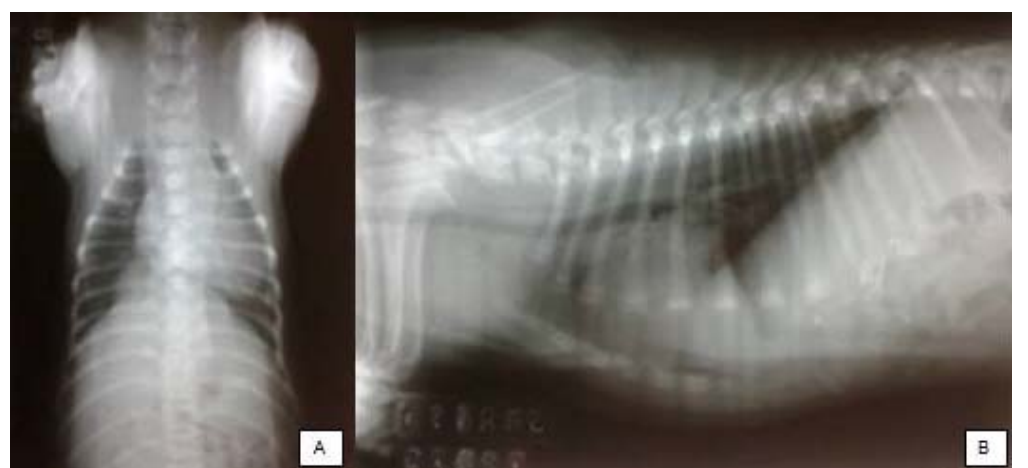

Figure 1. Ventrodorsal (A) and laterolateral (B) radiographs of a female, two-month-old dog with pleuroperitoneal hernia. Note cranial protrusion of the diaphragm in both projections; central (A) and ventral (B) position.

Hematological assessment revealed normocytic hypochromic anemia $(\mathrm{GV}=32 \%$; hemoglobin $=$ $9.6 \mathrm{~g} / \mathrm{dL} ; \mathrm{RBC}=4.71 \times 10^{6} / \mu \mathrm{L} ; \mathrm{MCV}=68 \mathrm{fL}$, $\mathrm{MCHC}=30 \%)$. No WBC abnormalities were noted. An increased activity of alkaline phosphatase (360.59 IU/L) was observed. Based on the results of the complementary examination, the patient was referred to laparoscopy in order to confirm the diagnosis and to attempt surgical repair.

Tramadol chloride $\left(4 \mathrm{mg} \mathrm{kg}^{-1}\right.$, IM) was given as premedication. Cephalothin (30 $\mathrm{mg} \mathrm{kg}^{-1}$, IV) was given for antimicrobial prophylaxis. General anesthesia was induced with propofol $\left(4 \mathrm{mg} \mathrm{kg}^{-1}\right.$,
IV), followed by epidural administration of an association of $2 \%$ lidocaine $\left(0.13 \mathrm{ml} \mathrm{kg}^{-1}\right), 0.5 \%$ bupivacaine $\left(0.13 \mathrm{ml} \mathrm{kg}^{-1}\right)$ and morphine $(0.1 \mathrm{mg}$ $\left.\mathrm{kg}^{-1}\right)$. General anesthesia was maintained using isoflurane vaporized in $100 \% \mathrm{O}_{2}$, in a semiclosed circuit.

The patient was positioned in dorsal recumbence and the ventral abdomen and thorax were prepared aseptically. An 1-cm mini-celiotomy was performed on the umbilicus scar for insertion of a $10-\mathrm{mm}$ trocar and a $12-\mathrm{mmHg}$ $\mathrm{CO}_{2}$ pneumoperitoneum was created. A $0^{\circ}$ $10-\mathrm{mm}$ telescope was passed through the trocar for primary abdominal examination and 
pleuroperitoneal hernia was confirmed (Fig. 2-A). The defect was positionedventrally to the right and affected approximately $25 \%$ of the diaphragmatic surface, confirming the left cardiac displacement seen in the chest radiographs.

A $10-\mathrm{mm}$ and a 5-mm instrument port was established on the right and left hypogastric areas, respectively, with laparoscopic guidance. A polypropylene mesh was cut in the shape of the defect and introduced into the abdominal cavity through the $10-\mathrm{mm}$ port. The mesh was placed over the defect edges. Intracorporeal sutures, using monofilament nylon 2-0 in a simple interrupted pattern, were carried out, taking bites on the mesh and the defect edges (Fig. 2-B).

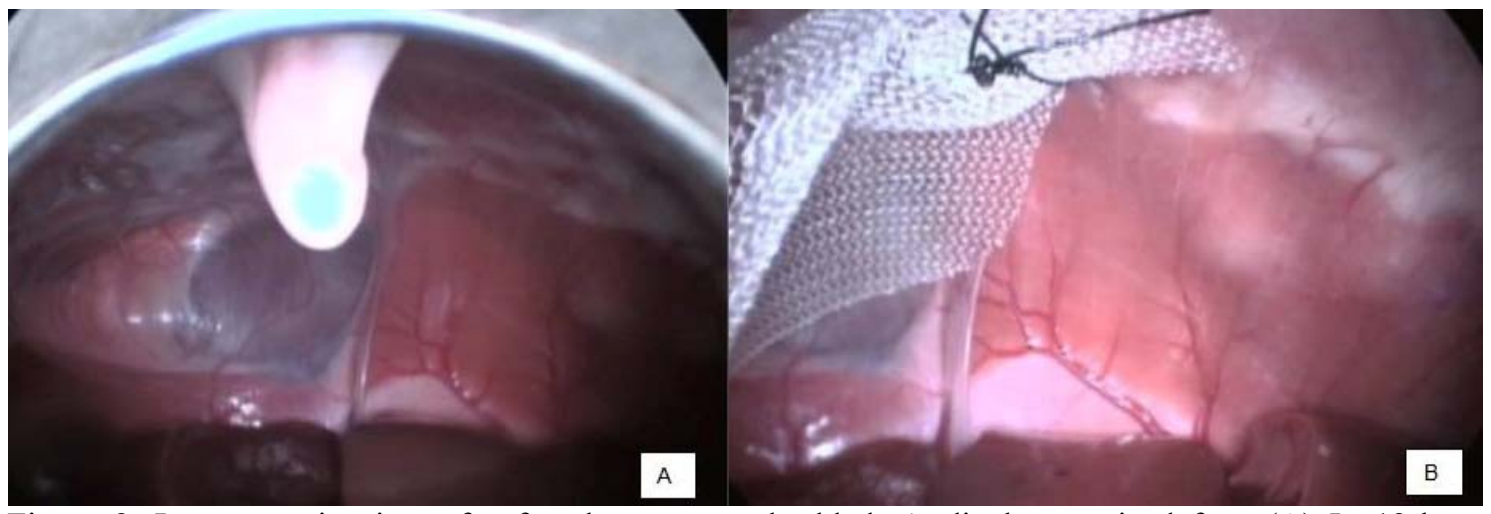

Figure 2. Laparoscopic view of a female, two-month-old dog's diaphragmatic defect. (A) In 12-hour position, the falciform ligament in observer. At the bottom, hepatic lobes are viewed. On the left side, a wide diaphragmatic defect involving almost $1 / 4$ of the muscle area. (B) Polypropylene mesh placed over the defect, following the application of the first intracorporeal suture.

The pneumoperitoneum was drained, the ports were withdrawn and wound closure was performed routinely in three layers. Immediate postoperative chest radiographs revealed residual pneumothorax in right hemithorax, but the diaphragm was intact and shows that no changes were found in the lungs (Fig. 3-A and B). No chest tube was used and successive intercostal thoracentesis for the management of residual pneumothorax were required up to 24 hours postoperatively. Following pneumothorax drainage, the patient recovered with no adverse events. Postoperative care included tramadol (4mg kg ${ }^{-1}, \mathrm{SC}$, TID, for 3 days) and meloxicam (0.1 $\mathrm{mg} \mathrm{kg}^{-1}, \mathrm{SC}$, SID, 3 days) for analgesia. The patient was discharged 48 hours after surgery.

The owner lived in a town far from the Veterinary Referral Hospital and the patient returned 45 days post-op for follow-up. Physical examination revealed normal nutritional and hydration status and pale mucosa. Abdominal palpation revealed pain. The patient had received the a dose of vaccine, as well as anthelmintic recently. New thoracic radiography was carried out, which revealed cardiac silhouette with preserved shape and volume, lungs presenting normal pattern, as well as preserved diaphragm and no evidence of thoracic deformations or pneumothorax (Fig. 3-C, D). On abdominal ultrasonography, small intestine mucosal thickening was observed, which was diagnosed as enteritis without connection to pleuroperitoneal hernia. The animal was given metronidazole orally $\left(15 \mathrm{mg} \mathrm{kg}^{-1}\right.$, BID for 20 days) and did not present clinical signs of enteritis within seven days of the beginning of the treatment.

Six months following surgery, the bitch was referred to laparoscopicassisted ovariohysterectomy. Routine physical examination and hematological tests were carried out along with new radiographic assessment (Figure 4). No abnormality was found and the patient was submitted to lap-spay. 


\section{Hartmann et al.}

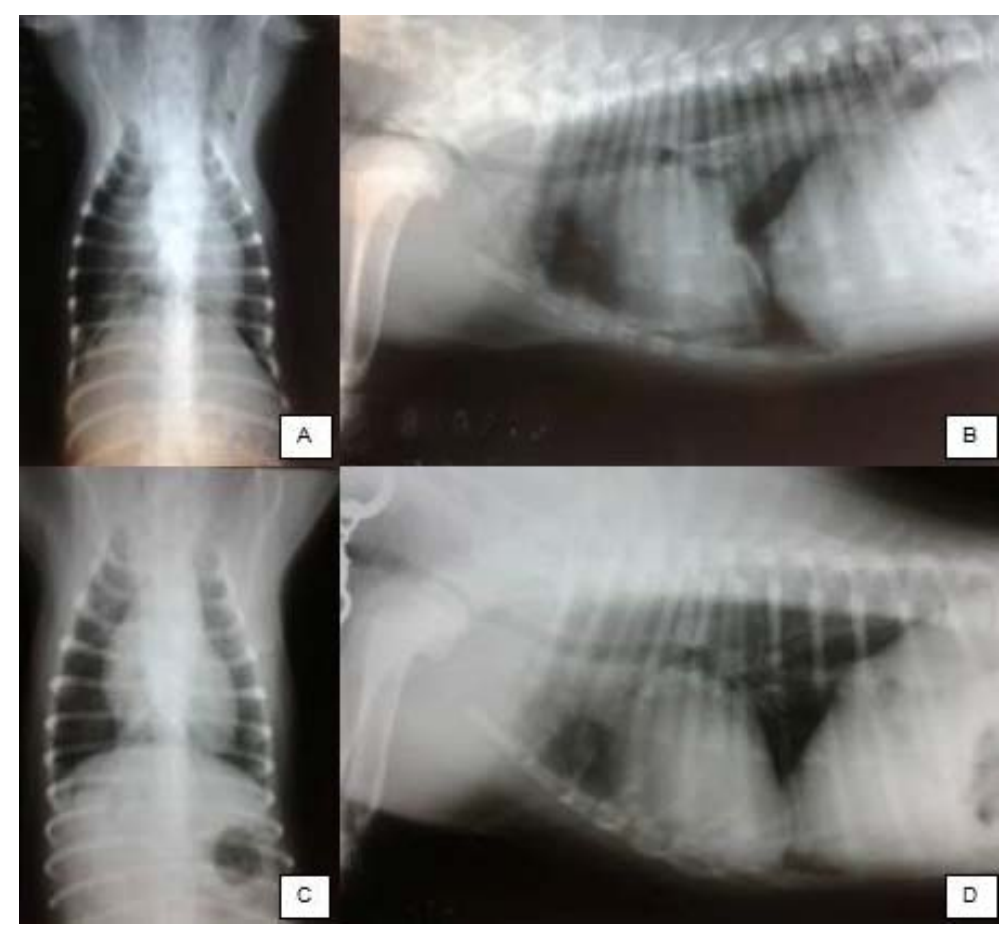

Figure 3. Female, two-month-old dog's postoperative chest radiographs revealing diaphragmatic silhouette integrity, heart positioned to its normal axis and residual pneumothorax (A and $\mathrm{B}$ ). Radiographs following 45 days of surgery reveals preserved diaphragmatic integrity and normal heart and lung aspect $(\mathrm{C}$ and $\mathrm{D})$.

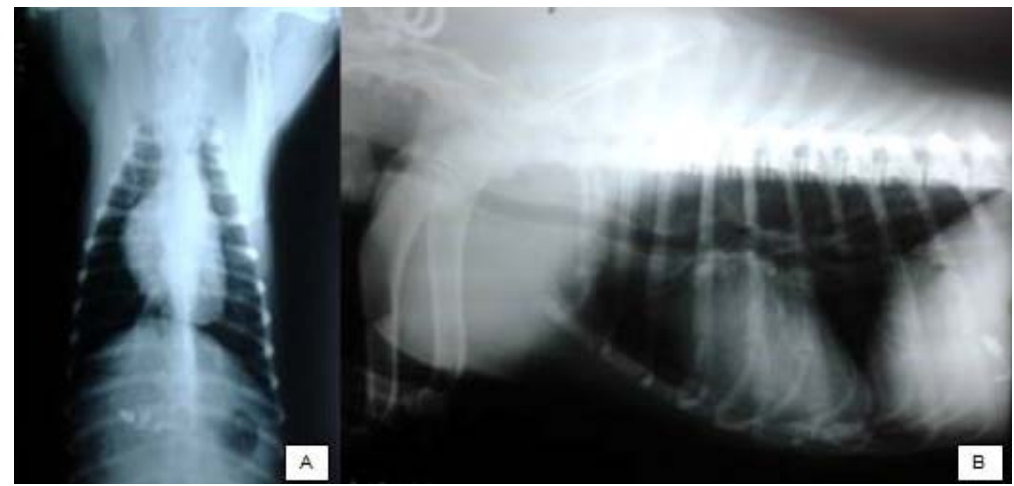

Figure 4. Female, eight-month-old dog's chest survey radiographs prior to laparoscopic spay showing preserved diaphragmatic integrity in dorsoventral (A) and laterolateral (B) projections.

A two-port laparoscopic-assisted approach was used for ovariohysterectomy. The abdominal cavity was closely inspected during surgery, with special regard to the diaphragm. Broad adhesions were found along the liver and the diaphragm surface, especially on the implantion area. Thus, it was not possible to directly view the mesh, as seen in Figure 5.
Adhesiolysis was not performed. The laparoscopic-assisted ovariohysterectomy was performed uneventfully. Following complete anesthetic recovery, the patient was discharged and convalesced at home. The last contact with the owner was made on the $120^{\text {th }}$ day post-op. no abnormalities were reported by the owner. 


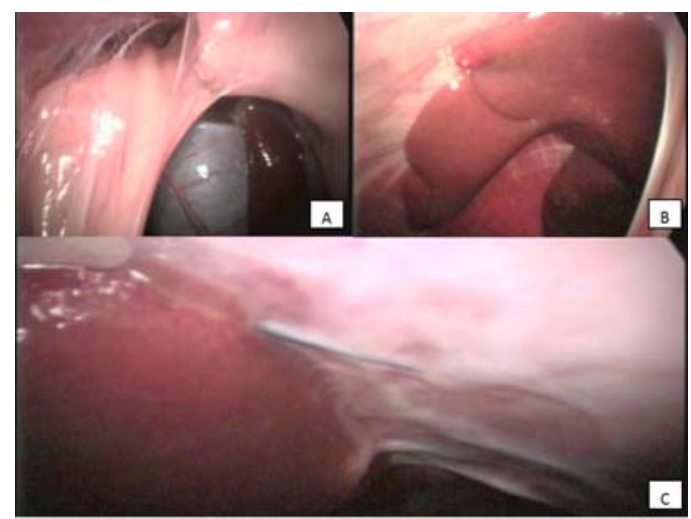

Figure 5. Laparoscopic view of the mesh implant site six months later, obtained during laparoscopicassisted ovariohysterectomy in a female, eight-month-old dog. (A) Adhesion involving the omentum and the abdominal wall, caudally to the liver. The patient was positioned in dorsal recumbence. (B) Right hepatic lobes attached to the diaphragmatic surface by wide intraperitoneal adhesions. (C) Nonabsorbable suture involved by capsular tissue enclosed by the diaphragm nearby the left hepatic lobe.

\section{DISCUSSION}

The etiology of congenital diaphragmatic hernia in humans is unknown, however it was noted that $2 \%$ of cases have familial incidence and $15 \%$ of cases have chromosomal abnormalities associated (Kesieme and Kesieme, 2011). Congenital left dorsolateral defect causing diaphragmatic hernia was reported in five of 27 puppies from three progenies in Golden Retrievers. Such findings are consistent with autosomal recessive inheritance of canine diaphragmatic defects (Valentine et al., 1988). Congenital absence of all or part of the diaphragm is known as an autosomal recessive disorder in cats (Burns et al., 2013). As there was no history of trauma to the animal of the present report and no evidence of chronic inflammation due to rupture on laparoscopic assessment, congenital disease was suspected.

Studies in mouse models and human specimens provided basis for understanding embryological origins of the diaphragmatic defect. Posterolateral defects of the left part of the diaphragm are clinically known as Bochdalek hernias in humans (Greer, 2013). The defect was seen on the right ventrolateral part of the diaphragm in the patient reported in the current study, which is known as Morgagni hernia in humans. Such hernia is described as a defect resulting from failure on the pleuroperitoneal membrane prior to union on the sternal and costal cartilages during embryogenesis (Kesieme and Kesieme, 2011).
Pleuroperitoneal hernias are often incidental and asymptomatic findings (Kesieme and Kesieme, 2011). However, the patient of the current report presented signs that raised suspicion on diaphragmatic dysfunction. The only case describing this type of hernia on the current literature was a Shar-pei with hiatal hernia and pleuroperitoneal hernia combined (Auger and Riley, 1997).

In another study, the authors have mentioned that there were only three other cases of cats diagnosed with pleuroperitoneal hernia at that time, all of them presenting respiratory distress. However, the hernia was an incidental finding in one patient (Cariou et al., 2009). The authors also hypothesized that congenital diaphragm defects are not as rare as mentioned in current literature, as more animals can be asymptomatic and live a normal life.

The main clinical signs of congenital diaphragmatic hernia are respiratory and gastrointestinal distress. In most cases of right side hernias in human patients, respiratory signs are present, and most cases of left side hernias, gastrointestinal signs are likely to occur (Kesieme and Kesieme, 2011). The patient of the present report also showed clinical signs, which is compatible to most reports.

In a retrospective study on peritoneopericardial hernias, $57.1 \%$ of affected dogs and $23.3 \%$ of affected cats had other concurrent congenital anomalies, such as umbilical hernia, 
supra-umbilical wall hernia, cryptorchidism, cleft palate, persistent pupillary membrane, intra and extra-hepatic portosystemic shunts, other cardiovascular defects and pectus excavatum and other vertebral abnormalities (Burns et al., 2013). Additionally, the most common hematologic abnormality was increased activity of alanine aminotransferase (ALT) on that study. The dog reported in the current study had no other congenital-related abnormalities. Increased alkaline phosphatase was the only alteration found on the patient's biochemical profile. There was no basis for increase in ALT in other cases of peritoneopericardial hernia in current literature, whereas the increase in alkaline phosphatase in the present report is believed to be associated to the patient's age.

Multiple radiographic projections, gastrointestinal contrast studies, positive or negative contrast for celiography and ultrasound are useful in the diagnosis of diaphragmatic hernia in dogs and cats. True diaphragmatic hernias may be confused with lung masses, since thoracic opacities are usually well delimited by the parietal pleura (Barbosa et al., 2008). Ultrasound proved to be accurate to identify the diaphragmatic defect in the current report, since the chest radiograph did not identify whether the apparent mass was pericardial, mediastinal, pulmonary or diaphragmatic in origin. The thoracic radiographs performed for the present report revealed caudal opacity. This condition could have been confused with other diseases in where ultrasound assessment could not be performed, as mentioned by others (Cariou et al., 2009). The position and contents of the hernia can be easily determined with the use of computed tomography, which also differentiates diaphragmatic hernias, mediastinal masses, bronchogenic cysts and other congenital malformations of the lung parenchyma (Kesieme and Kesieme, 2011). As there was no availability of CT in our case, laparoscopy was suggested for both complementary diagnosis and treatment.

Concerning surgical approach, a cat with pleuroperitoneal hernia underwent primary closure of the wound with a simple continuous suture using 3-0 polydioxanone (Cariou et al., 2009). A successful technique using a reverse latissimus dorsi flap was reported in a child following hernia recurrence (Barbosa et al., 2008). Autologous pericardium was also successfully used for repair of a peritoneopericardial hernia in a dog (Burns et al., 2013). In the present case, a synthetic mesh was chosen due to the lack of tissue to provide adequate primary closure of the defect. On the other hand, it would be better to use specific stapler for hernias to reduce operative time and technical difficult, because extensive training on intracorporeal knot suturing is required in order to reduce surgical time and provide secure mesh fixation. Unfortunately, as we did not have hernia stapler we used intracorporeal suture.

The repair of large congenital diaphragmatic defects using synthetic meshes caused recurrence, progressive deformity of the chest wall and restrictive lung disease in newborns (Voges et al., 1997). No special technique of pleuroperitoneal hernia repair was reported in dogs in current literature, either by conventional or laparoscopic surgery. However, for both traumatic and congenital diaphragmatic hernias the use of synthetic implants such as polypropylene mesh by laparotomy was well established.

In conclusion, this report is a contribution that brings a new perspective in management of this disease through total laparoscopic surgery, with possible advantages because it's a minimally invasive approach. The laparoscopic pleuroperitoneal diaphragmatic hernia repair using polypropylene mesh and intracorporeal suturing is feasible in dogs and provides both minimal invasion and a short convalescence for the patient.

\section{REFERENCES}

AUGER, J.M.; RILEY, S.M. Combined hiatal and pleuroperitoneal hernia in a Shar-pei. Can. Vet. J., v.38, p.640-642, 1997.

BARBOSA, R.F.; RODRIGUES, J.; CORREIAPINTO, J. et al. Repair of a large congenital diaphragmatic defect with a reverse latissimus dorsi muscle flap. Microsurgery, v.28, p.85-88, 2008.

BECK, C.A.C.; PIPPI, N.L.; BRUN, M.V. et al. Thoracoscopic techniques in diaphragmatic hernias: experimental study in dogs (Author's transl.). Cienc. Rural., v.34, p.1857-1863, 2004. 
BURNS, C.G.; BERGH, M.S.; McLOUGHLIN, M.A. Surgical and nonsurgical treatment of peritoneopericardial diaphragmatic hernia in dogs and cats: 58 cases (1999-2008). J. Am. Vet. Med. Assoc., v.242, p.643-650, 2013.

CARIOU, M.P.L.; SHIHAB, N.; KENNY, P. et al. Surgical management of an incidentally diagnosed true pleuroperitoneal hernia in a cat. $J$. Feline Med. Surg., v.11, p.873-877, 2009.

GREER, J.J. Current concepts on the pathogenesis and etiology of congenital diaphragmatic hernia: review. Respir. Physiol. Neurobiol., v.189, p.232-240, 2013.

HEDRICK, H.L. Management of prenatally diagnosed congenital diaphragmatic hernia. Semin. Fetal Neonat. Med., v.15, p.21-27, 2010.
HEDRICK, H.L.; CROMBLEHOLME, T.M.; FLAKE, A.W. et al. Right congenital diaphragmatic hernia: prenatal assessment and outcome. J. Pediatr. Surg., v.39, p.319-323, 2004.

KESIEME, E.B.; KESIEME, C.N. Congenital diaphragmatic hernia: review of current concept in surgical management. ISRN Surg. v.2011, p.18,2011

THRALL, D.E. Diagnóstico de radiologia veterinária. 5.ed. Rio de Janeiro: Elsevier, 2010. $856 \mathrm{p}$.

VALENTINE, B.A.; COOPER, B.J.; DIETZE, A.E. et al. Canine congenital diaphragmatic hernia. J. Vet. Intern. Med., v.2, p.109-112, 1988.

VOGES, A.K.; BERTRAND, S.; HILL, R.C. et al. True diaphragmatic hernia in a cat. Vet. Radiol. Ultrasoun. v.38, p.116-119, 1997. 